DOI: $10.15593 /$ RZhBiomeh/2016.3.08

УДК 796.422.14: 612.766.1

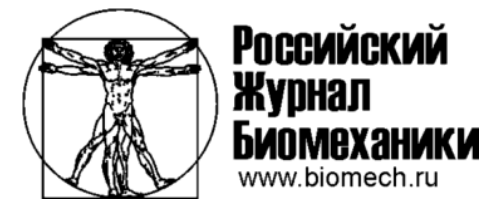

\title{
КРИТЕРИИ ОПТИМИЗАЦИИ СПЕЦИАЛЬНЫХ УПРАЖНЕНИЙ БЕГУНОВ НА СРЕДНИЕ ДИСТАНЦИИ
}

\author{
Л.Л. Ципин \\ Национальный государственный университет физической культуры, спорта и здоровья имени \\ П.Ф. Лесгафта, Россия, 190121, Санкт-Петербург, ул. Декабристов, 35, e-mail: \\ spb_biomechanics@rambler.ru
}

\begin{abstract}
Аннотация. Цель работы состоит в оптимизации специальных упражнений бегунов на средние дистанции на основе анализа фразовых траекторий мышц нижних конечностей в координатах «относительная длина - скорость сокращения мышцы». Рассмотрены следующие упражнения, применяемые на практике для развития силовой выносливости спортсменов: бег в подъем, многоскоки с ноги на ногу, бег с прыжками на каждый третий шаг и многоскоки на одной ноге. Упражнения выполнялись тремя квалифицированными спортсменами на ровной поверхности, в подъем с углами 4, 8, $12^{\circ}$. Оптимальность упражнений определялась по соответствию формы фазовых траекторий и положению на них периодов активности мышц, а также средней амплитуде электромиограмм при беге с соревновательной скоростью и при выполнении специальных упражнений. Качественный анализ фразовых траекторий позволил выявить специальные упражнения, наиболее близкие к соревновательному упражнению и превышающие его по средней амплитуде электромиограмм, характеризующей развиваемое мышцей усилие. Для более точного количественного анализа фразовых траекторий В качестве критериев оптимизации специальных упражнений предложено использовать коэфффициенты биомеханического соответствия, силового превышения и общей эфффективности упражнения. В результате показано, что оптимальными средствами воздействия на мышцы задней поверхности бедра спортсмена служат бег и бег с прыжками на каждый третий шаг в подъем с углом $12^{\circ}$, на мышцы передней поверхности бедра - все рассмотренные прыжковые упражнения, на мышцы задней поверхности голени - прыжковые упражнения и бег в подъем с углом $12^{\circ}$, который также обеспечивает равномерное распределение нагрузки на основные группы мышц.
\end{abstract}

Ключевые слова: бег на средние дистанции, специальные упражнения, фазовые траектории мышц, электрическая активность мышц, критерии оптимизации.

\section{ВВеДЕНИЕ}

В подготовке бегунов на средние дистанции центральное место занимает специальная физическая подготовка. Основным физическим качеством, от которого непосредственно зависит спортивный результат, является силовая выносливость. Существует большое количество специальных упражнений, направленных на развитие силовой выносливости бегунов: упражнения с отягощениями, прыжковые упражнения, бег с сопротивлением и в затрудненных условиях [7-9]. Показана, в частности, высокая эффективность бега и прыжков, выполняемых в подъем (в гору) $[4,5,14,15]$. Однако конкретные рекомендации по условиям применения этих упражнений и воздействию каждого из них на спортсменов малочисленны и носят преимущественно качественный характер.

(С) Ципин Л.Л., 2016

Ципин Леонид Львович, к.пед.н., профессор кафедры биомеханики, Санкт-Петербург 
Специальные упражнения должны не только оказывать на бегунов достаточное силовое воздействие, но и соответствовать двигательной специфике основного (соревновательного) упражнения, т.е. быть адекватными ему по кинематическим и динамическим характеристикам движений [1]. Наиболее полно такое соответствие позволяет оценить анализ активности двигательного анализатора. В этом отношении представляется перспективным применение метода фазового пространства для сравнения мышечной активности при выполнении основного и специальных упражнений [13]. В.П. Муравьев в своих исследованиях осуществил сравнение фазовых траекторий, а также электрической активности мышц при беге с максимальной скоростью и выполнении специальных упражнений [3]. А.В. Самсонова предложила сравнивать фазовые траектории мышц при спринтерском и барьерном беге на основе критериев эффективности и адекватности специальных упражнений [6]. На этом же принципе А.М. Доронин изучал специальные упражнения в спринтерском беге, волейболе и тяжелой атлетике [2]. Данный подход был также ранее применен для оценки эффективности специальных упражнений бегунов на средние дистанции [10]. Однако несовершенство методики получения фазовых траекторий мышц и способов количественного сравнения основного и специальных упражнений потребовало разработки более точных критериев эффективности специальных упражнений.

Цель работы заключалась в сравнительном анализе фазовых траекторий в координатах «относительная длина - скорость сокращения мышцы» и электрической активности мышц квалифицированных бегунов на средние дистанции при выполнении соревновательного и специальных упражнений, направленных на развитие силовой выносливости спортсменов.

\section{МАТЕРИАЛЫ И МЕТОДЫ ИССЛЕДОВАНИЯ}

В экспериментах участвовали три квалифицированных спортсмена, специализирующиеся в беге на 800 и 1500 м. Рост спортсменов - 173-178 см, вес 62-71 кг. Спортсмены выполняли бег на дистанции 800 м с соревновательной скоростью, а также применяемые на практике специальные упражнения для развития силовой выносливости: бег в подъем, многоскоки с ноги на ногу, бег с прыжками на каждый третий шаг и многоскоки на одной ноге. Специальные упражнения выполнялись как на ровной поверхности, так и в подъем с углами $4,8,12^{\circ}$. Скорость бега в подъем и бега с прыжками на каждый третий шаг составляла $4,0-4,5$ м/c, многоскоков с ноги на ногу - 3,9-4,8 м/с, многоскоков на одной ноге - 2,2-2,5 м/с. Бег в подъем и бег с прыжками на каждый третий шаг проводились на отрезках 200 м, многоскоки с ноги на ногу - 150 м, многоскоки на одной ноге -80 м. При изучении специальных упражнений с целью точного задания углов подъема использовалась специально сконструированная электрическая беговая дорожка. Мощность двигателя беговой дорожки составляла 3,5 кВт, длина приводной ленты - 2,5 м, ее ширина - 0,5 м, скорость движения ленты - 0-7 м/с. Моделирование упражнений на беговой дорожке осуществлялось с учетом того, что, как было ранее показано, отсутствуют достоверные различия между выполнением данных упражнений в естественных и лабораторных условиях [12]. Беговая дорожка применялась после предварительного обучения спортсменов в течение четырех занятий.

В процессе бега с соревновательной скоростью и выполнения специальных упражнений производились синхронная видеосъемка и регистрация электрической активности мышц нижней конечности: $m$. rectus femoris, $m$. biceps femoris, m. gastrocnemius. Видеосъемка осуществлялась камерой Casio Exilim Pro EX-F1 (Япония) с частотой 60 кадр/с, а запись и обработка электромиограмм - посредством восьмиканального аппаратно-программного комплекса «Миотон» (ОКБ «РИТМ», г. Таганрог, Россия) и программного обеспечения StabMed2. Частота дискретизации 
каналов электромиограмм - 200 Гц. По материалам видеосъемки рассчитывались морфометрические характеристики мышц и строились их фазовые траектории [13]. В качестве характеристики развиваемого мышцей усилия определялась средняя амплитуда электромиограмм [11].

\section{РЕЗУЛЬТАТЫ И ИХ ОБСУЖДЕНИЕ}

На рис. 1 представлены фазовые траектории m. rectus femoris и $m$. biceps femoris одного из испытуемых при выполнении четырех специальных упражнений в подъем с углом $4^{\circ}$.
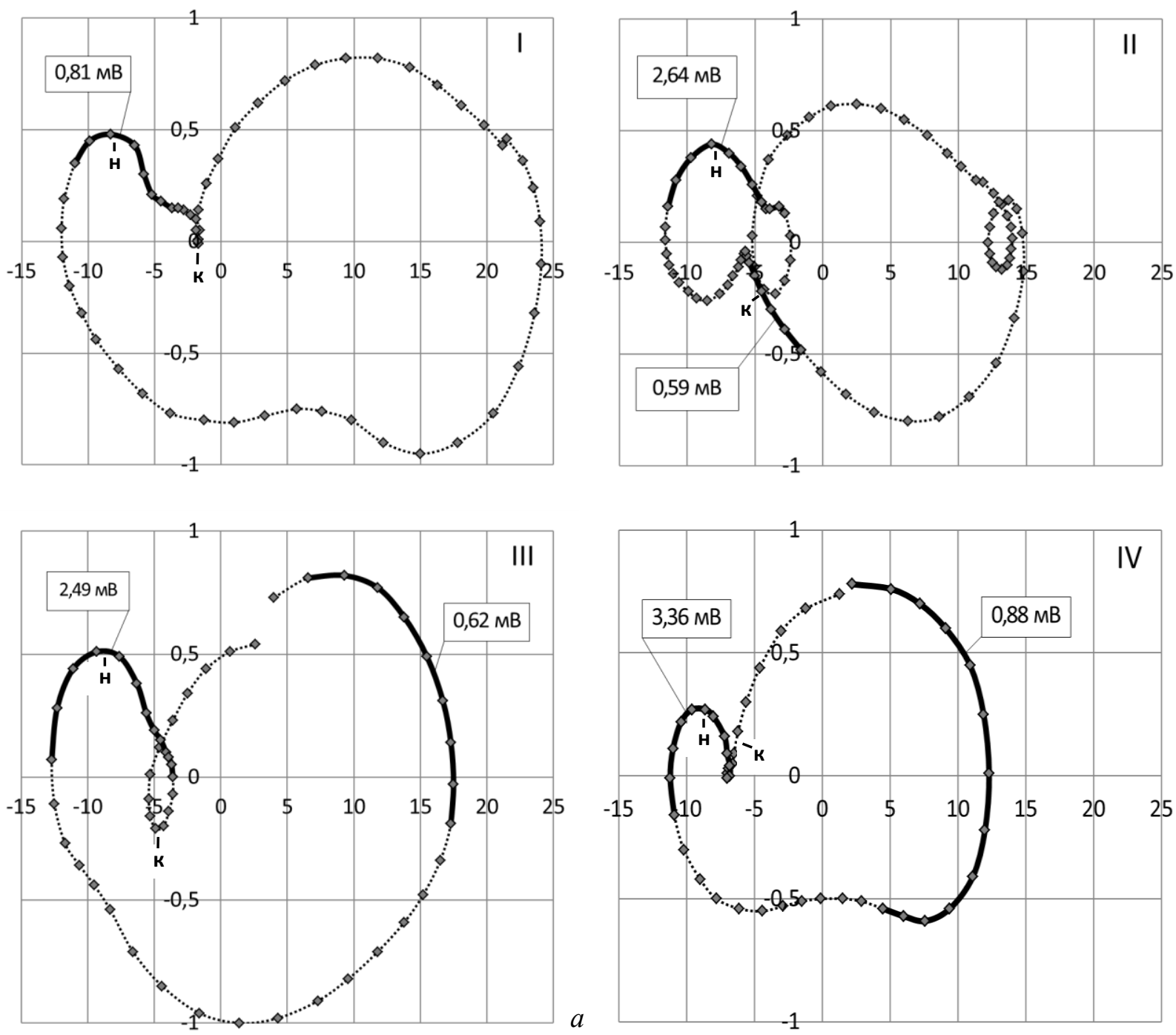

Рис. Фазовые траектории $m$. rectus femoris (a), m. biceps femoris (б) при выполнении упражнений в подъем с углом $4^{\circ}$. По горизонтали - относительная длина мышцы, \%; по вертикали - скорость сокращения мышцы, м/с. I - бег со скоростью 4,5 м/с, II - многоскоки с ноги на ногу, III - бег с прыжками на каждый третий шаг, IV - многоскоки на одной ноге. Жирные линии - мышца активна. Цифры на сносках - средняя амплитуда электромиограмм; н - начало опоры, к - конец опоры 

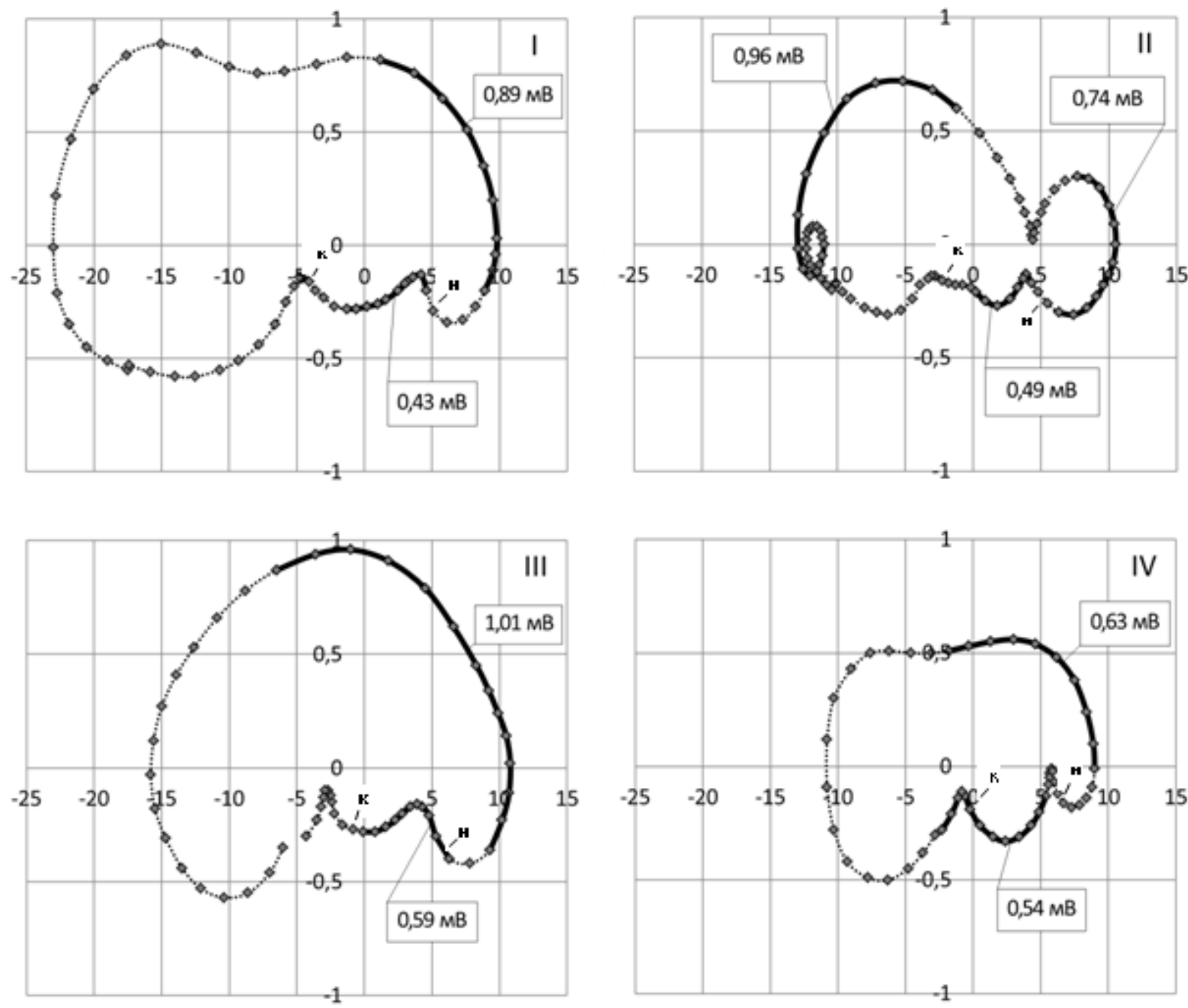

6

Рис. Окончание

Видно, что траектории существенно отличаются как по форме, так и по амплитуде изменения длины и скорости сокращения мышц. Отличия также касаются количества периодов активности мышц, их положения на фазовых траекториях и средней амплитуды электромиограмм в эти периоды.

Сравнение фазовых траекторий $m$. rectus femoris c соревновательным упражнением - бегом со скоростью 6,7 м/с, подробно рассмотренным в предыдущей статье [13], показало, что наибольшее соответствие наблюдается при беге в подъем (рис. $1, a)$. Однако в этом случае мышца активна только в течение одного периода, приходящегося на фазу опоры. Кроме того, с увеличением угла подъема происходит значительный сдвиг начала активности мышцы в сторону ее большей длины. Многоскоки с ноги на ногу и многоскоки на одной ноге характеризуются меньшими по сравнению с бегом значениями длины и скорости сокращения мышцы, хотя средняя амплитуда электромиограмм в первом, наиболее значимом для бега, периоде активности при выполнении многоскоков на одной ноге выше, чем в основном упражнении примерно в три раза. По форме фазовых траекторий и положению на них периодов активности к бегу с соревновательной скоростью близок бег с прыжками на каждый третий шаг. В отличие от других упражнений при таком беге с увеличением угла подъема средняя амплитуда электромиограмм меняется мало. 
Фазовые траектории $m$. biceps femoris имеют те же характерные особенности (рис. 1, б). При беге в подъем с увеличением угла происходит перераспределение активности с фазы опоры на фазу переноса ноги: средняя амплитуда электромиограммы увеличивается в первом периоде активности и уменьшается во втором. При выполнении многоскоков с ноги на ногу на фазовой траектории появляется третий период активности мышцы, связанный с необходимостью сильного сгибания голени в начале фазы переноса ноги, что несвойственно бегу. Наибольшее сходство с основным упражнением, как и для $m$. rectus femoris, наблюдается в беге с прыжками на каждый третий шаг, но при этом положение первого периода активности аналогично тому, что при беге с соревновательной скоростью только при углах подъема свыше $4^{\circ}$.

Фазовые траектории рассмотренных мышц при выполнении специальных упражнений двумя другими испытуемыми принципиально не отличаются. Таким образом, можно заключить, что проведенный качественный анализ позволяет дать общую характеристику специальных упражнений бегунов. Но для того чтобы более точно оценить соответствие организации мышечной активности при выполнении основного и специальных упражнений, силовое воздействие каждого из них, необходимо разработать количественные критерии оптимизации.

В основу разработки критериев оптимизации специальных упражнений было положено то обстоятельство, что различия фазовых траекторий мышц касаются прежде всего координат точек начала наиболее значимых периодов активности. Для рассмотренных мышц это периоды, соответствующие или предшествующие фазе опоры в беге. Положение точек фазовой траектории мышц может быть задано полярными координатами. Их применение оправдано тем, что в данном случае полярный радиус с физиологической точки зрения характеризует величину сенсорного притока, а полярный угол - структуру сенсорного притока в центральную нервную систему от афферентов работающей мышцы. Известно, что в состав мышечных веретен как комплексных сенсорных рецепторов поперечнополосатых мышц входят несколько разновидностей интрафузальных мышечных волокон, каждая из которых является отдельным специфическим сенсорным рецептором, реагирующим на длину мышцы или на скорость ее сокращения. Таким образом, можно говорить о дифференциации сенсорного притока от мышечных веретен в высшие нервные центры и, соответственно, о величине и структуре этого притока. Под структурой сенсорного притока в данном случае понимается соотношение активности сенсорных рецепторов, реагирующих на длину мышцы и на скорость ее сокращения. Поскольку полярный радиус точек фазовой траектории определяется одновременно длиной мышцы и скоростью ее сокращения, а полярный угол - их соотношением, то их уместно использовать для общей характеристики сенсорного притока.

Сравнение показателей активности двигательного анализатора позволяет определить степень биомеханического соответствия техники основного и специальных упражнений. При этом величина электрической активности мышцы дает представление о развиваемом ею усилии.

В качестве критериев оптимизации специальных упражнений, направленных на развитие силовой выносливости спортсменов, предложено использовать следующие коэффициенты:

$$
K_{b}=K_{b_{1}} \cdot K_{b_{2}},
$$

где $K_{b}$ - коэффициент биомеханического соответствия специального упражнения, $K_{b_{1}}$ и $K_{b_{2}}-$ коэффициенты величины и структуры сенсорного притока от афферентов работающей мышцы. 


$$
\begin{gathered}
K_{b_{1}}=1-\frac{\left|R_{s e}-R_{m e}\right|}{R_{m e}} ; \\
K_{b_{2}}=\left|1-\frac{\left|\varphi_{s e}-\varphi_{m e}\right|}{\pi}\right|,
\end{gathered}
$$

где $R_{s e}, R_{m e}, \varphi_{s e}, \varphi_{m e}$ - полярные координаты точек фазовых траекторий начала наиболее значимых периодов активности мышцы при выполнении специального и основного упражнений $(-\pi \leq \varphi \leq \pi)$.

$$
K_{p}=\frac{A_{s e}}{A_{m e}},
$$

где $K_{p}$ - коэффициент силового превышения специального упражнения, $A_{s e}$ и $A_{m e}-$ средняя амплитуда электромиограмм в наиболее значимые периоды активности мышцы при выполнении специального и основного упражнений.

$$
K_{o}=K_{b} \cdot K_{p},
$$

где $K_{o}$ - коэффициент общей эффективности специального упражнения.

Коэффициенты $K_{b 1}$ и $K_{b 2}$ принимают максимальное значение, равное единице, когда активация мышцы при выполнении основного и специального упражнений наступает при одной и той же относительной длине и скорости сокращения, а минимальное значение, равное нулю, - при их наибольшей разнице.

В таблице приведены средние значения рассчитанных аналитически коэффициентов, которые характеризуют выполненные тремя спортсменами специальные упражнения.

Поскольку все упражнения направлены на развитие силовой выносливости, необходимо выделить те их них, которые превышают основное упражнение по силовому воздействию, т.е. для которых $K_{p}>1$. Если для $m$. rectus femoris и $m$. gastrocnemius к таким упражнениям относятся, все за исключением бега в подъем с углом менее $8^{\circ}$, то для $m$. biceps femoris лишь три упражнения: бег в подъем, многоскоки с ноги на ногу и бег с прыжками на каждый третий шаг в подъем с углом $12^{\circ}-$ отвечают данному требованию. Хотя по силовому воздействию на m. biceps femoris эти упражнения различаются мало, по биомеханическому соответствию, т.е. по значению $K_{b}$, бег в подъем и бег с прыжками на каждый третий шаг существенно превосходят многоскоки с ноги на ногу. Для них также отмечаются высокие значения $K_{o}$. Таким образом, данные упражнения могут считаться оптимальным средством воздействия на мышцы задней поверхности бедра бегуна.

Как следует из таблицы, прыжковые упражнения оказывают на m. rectus femoris более интенсивное силовое воздействие по сравнению с бегом в подъем. Для них $K_{p}$ находится в диапазоне 2,45-3,29, причем с увеличением угла подъема он немного уменьшается или остается примерно постоянным. Биомеханическое соответствие упражнений различается незначительно. $K_{b}$ так же, как и $K_{p}$, с увеличением угла подъема немного уменьшается. Из этого следует, что рассмотренные прыжковые упражнения оптимальны для развития мышц передней поверхности бедра бегуна. 
Коэффициенты эффективности специальных упражнений бегунов на средние дистанции, $M \pm m(n=3)$

\begin{tabular}{|c|c|c|c|c|c|c|c|c|c|c|}
\hline \multirow{3}{*}{ Упражнение } & \multirow{3}{*}{$\begin{array}{l}\sum_{0}^{\pi} \\
0 \\
0 \\
0 \\
0 \\
\vdots \\
0 \\
\vdots \\
\nu\end{array}$} & \multicolumn{9}{|c|}{ Мышца } \\
\hline & & \multicolumn{3}{|c|}{ m. rectus femoris } & \multicolumn{3}{|c|}{ m. biceps femoris } & \multicolumn{3}{|c|}{ m. gastrocnemius } \\
\hline & & $K_{b}$ & $K_{p}$ & $K_{o}$ & $K_{b}$ & $K_{p}$ & $K_{o}$ & $K_{b}$ & $K_{p}$ & $K_{o}$ \\
\hline \multirow{3}{*}{ Бег в подъем } & $4^{\circ}$ & $\begin{array}{l}0,85 \pm \\
\pm 0,01\end{array}$ & $\begin{array}{l}0,83 \pm \\
\pm 0,03\end{array}$ & $\begin{array}{l}0,70 \pm \\
\pm 0,02\end{array}$ & $\begin{array}{l}0,62 \pm \\
\pm 0,06\end{array}$ & $\begin{array}{l}0,71 \pm \\
\pm 0,04\end{array}$ & $\begin{array}{l}0,44 \pm \\
\pm 0,07\end{array}$ & $\begin{array}{l}0,75 \pm \\
\pm 0,02\end{array}$ & $\begin{array}{l}0,83 \pm \\
\pm 0,05\end{array}$ & $\begin{array}{l}0,62 \pm \\
\pm 0,04\end{array}$ \\
\hline & $8^{\circ}$ & $\begin{array}{l}0,70 \pm \\
\pm 0,02\end{array}$ & $\begin{array}{l}1,14 \pm \\
\pm 0,06\end{array}$ & $\begin{array}{l}0,79 \pm \\
\pm 0,02\end{array}$ & $\begin{array}{l}0,65 \pm \\
\pm 0,08\end{array}$ & $\begin{array}{l}0,84 \pm \\
\pm 0,05\end{array}$ & $\begin{array}{l}0,53 \pm \\
\pm 0,04\end{array}$ & $\begin{array}{l}0,58 \pm \\
\pm 0,08\end{array}$ & $\begin{array}{l}0,86 \pm \\
\text { м0,03 }\end{array}$ & $\begin{array}{l}0,50 \pm \\
\pm 0,07\end{array}$ \\
\hline & $12^{\circ}$ & $\begin{array}{l}0,56 \pm \\
\pm 0,03\end{array}$ & $\begin{array}{l}1,64 \pm \\
\pm 0,06\end{array}$ & $\begin{array}{l}0,91 \pm \\
\pm 0,05\end{array}$ & $\begin{array}{l}0,83 \pm \\
\pm 0,12\end{array}$ & $\begin{array}{l}1,26 \pm \\
\pm 0,09\end{array}$ & $\begin{array}{l}1,05 \pm \\
\pm 0,17\end{array}$ & $\begin{array}{l}0,57 \pm \\
\text { м0,09 }\end{array}$ & $\begin{array}{l}1,14 \pm \\
\pm 0,02\end{array}$ & $\begin{array}{l}0,65 \pm \\
\pm 0,09\end{array}$ \\
\hline \multirow{4}{*}{$\begin{array}{c}\text { Многоскоки } \\
\text { с ноги } \\
\text { на ногу }\end{array}$} & $0^{\circ}$ & $\begin{array}{l}0,82 \pm \\
\pm 0,01\end{array}$ & $\begin{array}{l}2,86 \pm \\
\pm 0,05\end{array}$ & $\begin{array}{l}2,33 \pm \\
\pm 0,04\end{array}$ & $\begin{array}{l}0,31 \pm \\
\pm 0,02\end{array}$ & $\begin{array}{l}0,48 \pm \\
\pm 0,06\end{array}$ & $\begin{array}{l}0,15 \pm \\
\pm 0,01\end{array}$ & $\begin{array}{l}0,38 \pm \\
\pm 0,05\end{array}$ & $\begin{array}{l}1,38 \pm \\
\pm 0,17\end{array}$ & $\begin{array}{l}0,51 \pm \\
\pm 0,01\end{array}$ \\
\hline & $4^{\circ}$ & $\begin{array}{l}0,91 \pm \\
\pm 0,02\end{array}$ & $\begin{array}{l}2,56 \pm \\
\pm 0,08\end{array}$ & $\begin{array}{l}2,33 \pm \\
\pm 0,03\end{array}$ & $\begin{array}{l}0,31 \pm \\
\pm 0,01\end{array}$ & $\begin{array}{l}0,64 \pm \\
\pm 0,03\end{array}$ & $\begin{array}{l}0,20 \pm \\
\pm 0,01\end{array}$ & $\begin{array}{l}0,52 \pm \\
\pm 0,04\end{array}$ & $\begin{array}{l}1,31 \pm \\
\pm 0,13\end{array}$ & $\begin{array}{l}0,67 \pm \\
\pm 0,02\end{array}$ \\
\hline & $8^{\circ}$ & $\begin{array}{l}0,73 \pm \\
\pm 0,01\end{array}$ & $\begin{array}{l}2,69 \pm \\
\pm 0,03\end{array}$ & $\begin{array}{l}1,98 \pm \\
\pm 0,02\end{array}$ & $\begin{array}{l}0,33 \pm \\
\pm 0,05\end{array}$ & $\begin{array}{l}0,85 \pm \\
\pm 0,04\end{array}$ & $\begin{array}{l}0,28 \pm \\
\pm 0,03\end{array}$ & $\begin{array}{l}0,55 \pm \\
\pm 0,02\end{array}$ & $\begin{array}{l}1,19 \pm \\
\pm 0,10\end{array}$ & $\begin{array}{l}0,66 \pm \\
\pm 0,08\end{array}$ \\
\hline & $12^{\circ}$ & $\begin{array}{l}0,78 \pm \\
\pm 0,02\end{array}$ & $\begin{array}{l}2,45 \pm \\
\pm 0,04\end{array}$ & $\begin{array}{l}1,92 \pm \\
\pm 0,03\end{array}$ & $\begin{array}{l}0,41 \pm \\
\pm 0,09\end{array}$ & $\begin{array}{l}1,07 \pm \\
\pm 0,09\end{array}$ & $\begin{array}{l}0,43 \pm \\
\pm 0,07\end{array}$ & $\begin{array}{l}0,47 \pm \\
\pm 0,02\end{array}$ & $\begin{array}{l}1,33 \pm \\
\pm 0,05\end{array}$ & $\begin{array}{l}0,63 \pm \\
\pm 0,01\end{array}$ \\
\hline \multirow{4}{*}{$\begin{array}{c}\text { Бег } \\
\text { с прыжками } \\
\text { на каждый } \\
\text { третий шаг }\end{array}$} & $0^{\circ}$ & $\begin{array}{l}0,94 \pm \\
\pm 0,01\end{array}$ & $\begin{array}{l}2,70 \pm \\
\pm 0,04\end{array}$ & $\begin{array}{l}2,52 \pm \\
\pm 0,05\end{array}$ & $\begin{array}{l}0,73 \pm \\
\pm 0,03\end{array}$ & $\begin{array}{l}0,65 \pm \\
\pm 0,08\end{array}$ & $\begin{array}{l}0,48 \pm \\
\pm 0,08\end{array}$ & $\begin{array}{l}0,67 \pm \\
\text { м0,04 }\end{array}$ & $\begin{array}{l}1,49 \pm \\
\pm 0,19\end{array}$ & $\begin{array}{l}1,02 \pm \\
\pm 0,18\end{array}$ \\
\hline & $4^{\circ}$ & $\begin{array}{l}0,95 \pm \\
\pm 0,02\end{array}$ & $\begin{array}{l}2,48 \pm \\
\pm 0,08\end{array}$ & $\begin{array}{l}2,36 \pm \\
\pm 0,05\end{array}$ & $\begin{array}{l}0,85 \pm \\
\pm 0,03\end{array}$ & $\begin{array}{l}0,85 \pm \\
\pm 0,04\end{array}$ & $\begin{array}{l}0,73 \pm \\
\pm 0,06\end{array}$ & $\begin{array}{l}0,69 \pm \\
\pm 0,02\end{array}$ & $\begin{array}{l}1,41 \pm \\
\pm 0,26\end{array}$ & $\begin{array}{l}0,96 \pm \\
\pm 0,18\end{array}$ \\
\hline & $8^{\circ}$ & $\begin{array}{l}0,91 \pm \\
\pm 0,02\end{array}$ & $\begin{array}{l}2,59 \pm \\
\pm 0,04\end{array}$ & $\begin{array}{l}2,35 \pm \\
\pm 0,03\end{array}$ & $\begin{array}{l}0,77 \pm \\
\pm 0,08\end{array}$ & $\begin{array}{l}0,94 \pm \\
\pm 0,03\end{array}$ & $\begin{array}{l}0,72 \pm \\
\pm 0,05\end{array}$ & $\begin{array}{l}0,54 \pm \\
\pm 0,09\end{array}$ & $\begin{array}{l}1,27 \pm \\
\pm 0,08\end{array}$ & $\begin{array}{l}0,70 \pm \\
\pm 0,15\end{array}$ \\
\hline & $12^{\circ}$ & $\begin{array}{l}0,83 \pm \\
\pm 0,02\end{array}$ & $\begin{array}{l}2,74 \pm \\
\pm 0,07\end{array}$ & $\begin{array}{l}2,27 \pm \\
\pm 0,02\end{array}$ & $\begin{array}{l}0,85 \pm \\
\pm 0,05\end{array}$ & $\begin{array}{l}1,19 \pm \\
\pm 0,10\end{array}$ & $\begin{array}{l}1,00 \pm \\
\pm 0,03\end{array}$ & $\begin{array}{l}0,53 \pm \\
\pm 0,07\end{array}$ & $\begin{array}{l}1,28 \pm \\
\pm 0,06\end{array}$ & $\begin{array}{l}0,69 \pm \\
\pm 0,11\end{array}$ \\
\hline \multirow{4}{*}{$\begin{array}{c}\text { Многоскоки } \\
\text { на одной ноге }\end{array}$} & $0^{\circ}$ & $\begin{array}{l}0,73 \pm \\
\pm 0,03\end{array}$ & $\begin{array}{l}3,29 \pm \\
\pm 0,10\end{array}$ & $\begin{array}{l}2,40 \pm \\
\pm 0,04\end{array}$ & $\begin{array}{l}0,37 \pm \\
\pm 0,05\end{array}$ & $\begin{array}{l}0,52 \pm \\
\pm 0,04\end{array}$ & $\begin{array}{l}0,19 \pm \\
\pm 0,03\end{array}$ & $\begin{array}{l}0,56 \pm \\
\pm 0,08\end{array}$ & $\begin{array}{l}1,79 \pm \\
\pm 0,13\end{array}$ & $\begin{array}{l}0,92 \pm \\
\pm 0,14\end{array}$ \\
\hline & $4^{\circ}$ & $\begin{array}{l}0,78 \pm \\
\pm 0,02\end{array}$ & $\begin{array}{l}3,03 \pm \\
\pm 0,10\end{array}$ & $\begin{array}{l}2,37 \pm \\
\pm 0,05\end{array}$ & $\begin{array}{l}0,41 \pm \\
\pm 0,06\end{array}$ & $\begin{array}{l}0,61 \pm \\
\pm 0,07\end{array}$ & $\begin{array}{l}0,25 \pm \\
\pm 0,03\end{array}$ & $\begin{array}{l}0,62 \pm \\
\pm 0,08\end{array}$ & $\begin{array}{l}1,30 \pm \\
\pm 0,04\end{array}$ & $\begin{array}{l}0,77 \pm \\
\pm 0,10\end{array}$ \\
\hline & $8^{\circ}$ & $\begin{array}{l}0,67 \pm \\
\pm 0,04\end{array}$ & $\begin{array}{l}2,92 \pm \\
\pm 0,10\end{array}$ & $\begin{array}{l}1,95 \pm \\
\pm 0,05\end{array}$ & $\begin{array}{l}0,54 \pm \\
\pm 0,07\end{array}$ & $\begin{array}{l}0,68 \pm \\
\pm 0,06\end{array}$ & $\begin{array}{l}0,37 \pm \\
\pm 0,08\end{array}$ & $\begin{array}{l}0,76 \pm \\
\pm 0,10\end{array}$ & $\begin{array}{l}1,31 \pm \\
\pm 0,03\end{array}$ & $\begin{array}{l}0,95 \pm \\
\pm 0,15\end{array}$ \\
\hline & $12^{\circ}$ & $\begin{array}{l}0,56 \pm \\
\pm 0,01\end{array}$ & $\begin{array}{l}2,77 \pm \\
\pm 0,09\end{array}$ & $\begin{array}{l}1,56 \pm \\
\pm 0,03\end{array}$ & $\begin{array}{l}0,54 \pm \\
\pm 0,10\end{array}$ & $\begin{array}{l}0,84 \pm \\
\pm 0,05\end{array}$ & $\begin{array}{l}0,45 \pm \\
\pm 0,08\end{array}$ & $\begin{array}{l}0,73 \pm \\
\pm 0,07\end{array}$ & $\begin{array}{l}1,54 \pm \\
\pm 0,06\end{array}$ & $\begin{array}{l}1,08 \pm \\
\pm 0,08\end{array}$ \\
\hline
\end{tabular}

Аналогичная тенденция характерна для прыжковых упражнений в отношении m. gastrocnemius с той лишь разницей, что силовое воздействие на нее меньше, чем на $m$. rectus femoris. Это приближает прыжковые упражнения к бегу в подъем с углом $12^{\circ}$. Каждое из этих упражнений может эффективно воздействовать на мышцы задней 
поверхности голени. Несколько отличаются от других многоскоки на одной ноге, при выполнении которых $K_{b}$ и $K_{p}$, а следовательно и $K_{o}$, принимают более высокие значения. Важно, что общая эффективность воздействия специальных упражнений на $m$. gastrocnemius почти не зависит от угла подъема.

При выполнении специальных упражнений для спортсменов имеет значение равномерное распределение нагрузки на основные группы мышц. Этому требованию в наибольшей степени отвечает бег в подъем с углом $12^{\circ}$, при котором коэффициенты $K_{b}, K_{p}$ и $K_{o}$ принимают близкие для рассмотренных мышц значения.

\section{ЗАКЛЮЧЕНИЕ}

Сравнение фазовых траекторий и электрической активности мышц спортсменов на основе предложенных коэффициентов биомеханического соответствия, силового превышения и общей эффективности специального упражнения дает возможность использовать последние в качестве количественных критериев оптимизации упражнений. Они позволяют направленно подбирать специальные упражнения и условия их применения для акцентированного воздействия на различные группы мышц бегунов на средние дистанции. В результате компенсируются недостатки в силовой подготовке спортсменов без нарушения структуры движений при беге с соревновательной скоростью. Данный подход может быть также реализован в других циклических видах спорта, связанных с проявлением силовой выносливости, таких как лыжные гонки, гребля, велоспорт.

\section{БЛАГОДАРНОСТИ}

Исследование проведено в рамках государственного задания Национального государственного университета физической культуры, спорта и здоровья имени П.Ф. Лесгафта на выполнение научно-исследовательской работы «Повышение эффективности применения упражнений специальной силовой направленности в подготовке квалифицированных спортсменов циклических видов спорта и спортивных единоборств на основе биомеханического анализа стереотипности и состава двигательных действий соревновательного упражнения» (приказ Минспорта России от 25.12. 2015 г. № 1247).

\section{СПИСОК ЛИТЕРАТУРЫ}

1. Верхошанский Ю.В. Основы специальной силовой подготовки в спорте. - М.: Советский спорт, 2013. - 216 c.

2. Доронин А.М. Физические упражнения как результат интеграции активности двигательного аппарата в качестве анализатора, двигателя и рекуператора энергии: автореф. дис. ... д-ра пед. наук. - Майкоп, 1999. - 46 с.

3. Муравьев В.П. Техническая подготовка в беге на короткие дистанции с учетом формирования двигательных программ: дис. ... канд. пед. наук. - Л., 1991. - 166 с.

4. Нарскин Г.И. Структура тренировочных нагрузок скоростно-силовой направлености квалифицированных бегунов на средние дистанции в годичном цикле тренировки: дис. ... канд. пед. наук. - Минск, 1988. - 160 с.

5. Нурмекиви А.А. О применении продолжительного бега и бега в гору в тренировке бегунов на средние и длинные дистанции в подготовительном периоде: автореф. дис. ... канд. пед. наук. Тарту, 1974. - $21 \mathrm{c.}$

6. Самсонова А.В. Моторные и сенсорные компоненты биомеханической структуры физических упражнений: дис. ... д-ра пед. наук. - СПб., 1997. - 310 с.

7. Селуянов В.Н. Подготовка бегуна на средние дистанции. - М.: ТВТ Дивизион, 2007. - 112 с. 
8. Сидоренко М.М. Специальные упражнения для обучения и тренировки бегуна // Тренажеры и специальные упражнения в легкой атлетике / под ред. В.Г. Алабина. - 2-е изд., перераб. и доп. - М.: Физкультура и спорт, 1982. - С. 23-31.

9. Суслов Ф.П., Кулаков В.Н. Бег на средние, длинные и сверхдлинные дистанции // Книга тренера по легкой атлетике / под ред. Л.С. Хоменкова. - 3-е изд., перераб. - М.: Физкультура и спорт, 1987. C. $177-217$.

10. Ципин Л.Л. Специальные упражнения сопряженного воздействия как средство тренировки бегунов на средние дистанции в подготовительном периоде: дис. ... канд. пед. наук. - СПб., 1991. - 218 с.

11. Ципин Л.Л., Захаров Ф.Е. Оценка динамической силы мышц спортсменов по показателям их электрической активности // Культура физическая и здоровье. - 2013. - № 1 (43). - С. 51-54.

12. Ципин Л.Л. Особенности выполнения циклических упражнений в естественных и лабораторных условиях // Культура физическая и здоровье. - 2015. - № 4 (55). - С. 68-72.

13. Ципин Л.Л. Применение фазового пространства для анализа мышечной активности при беге // Российский журнал биомеханики. - 2015. - Т. 19, № 4. - С. 421-429.

14. Belotti P., Fucci S. Come si allenono gli corridori finlandesi // Atletoco. - 1973. - № 7. - P. 45.

15. Billouin A. L'entrainement des cadets et juniors aux courses de fond // Revue d'AFFA. - 1985. P. 48-52.

\section{SPECIAL EXERCISES OPTIMIZATION CRITERIA FOR MIDDLE-DISTANCE RUNNERS}

\section{L.L. Tsipin (St. Petersburg, Russia)}

The objective of the present study is to optimize special exercises for middle-distance runners based on the analysis of phase trajectories of the muscles of the lower extremities in the "relative length - muscle contraction speed" coordinates. The following exercises that are used in practice for the purposes of development of strength endurance of athletes have been considered: uphill running, foot-to-foot multi-jumps, running with jumps on every third step, and one-leg multi-jumps. The exercises were performed by three qualified athletes on a level surface and at an inclination at the angles of 4, 8, and 12 degrees. The optimality of exercises was defined on the basis of their compliance with the form of phase trajectories and with the position of periods of muscle activity therein as well as with the average electromyogram amplitude while running at a race speed and performing special exercises. The qualitative analysis of phase trajectories has revealed special exercises that are the closest to the competitive exercise and that exceed the latter in terms of its average electromyogram amplitude, which characterizes the force developed by the muscles. The use of factors of biomechanical conformity, excess power, and overall effectiveness of the exercise has been suggested for a more accurate quantitative analysis of phase trajectories as optimization of special exercises. The result demonstrates that the optimal means of impact on athlete's hamstring muscle are uphill running and uphill running with jumps on every third step at an angle of 12 degrees; the optimal means of impact on athlete's front thigh muscles, all the considered jumping exercises; and the optimal means of impact on athlete's calves are jumping exercises and uphill running at an angle of 12 degrees, which also ensures a uniform distribution of the load on the major muscle groups.

Key words: middle-distance running, special exercises, phase trajectories of muscles, electrical activity of muscles, optimization criteria. 